\title{
BMJ Open How do iLead? Validation of a scale measuring active and passive implementation leadership in Swedish healthcare
}

\author{
Rebecca Mosson, ${ }^{1,2}$ Ulrica von Thiele Schwarz, ${ }^{1,3}$ Henna Hasson, ${ }^{1,2}$ \\ Robert Lundmark, ${ }^{1}$ Anne Richter ${ }^{1,2}$
}

To cite: Mosson $\mathrm{R}$, von Thiele Schwarz U, Hasson $\mathrm{H}$, et al. How do iLead? Validation of a scale measuring active and passive implementation leadership in Swedish healthcare. BMJ Open 2018;8:e021992. doi:10.1136/ bmjopen-2018-021992

- Prepublication history and additional material for this paper are available online. To view these files, please visit the journal online (http://dx.doi. org/10.1136/bmjopen-2018021992).

Received 30 January 2018 Revised 17 April 2018 Accepted 1 June 2018
Check for updates

${ }^{1}$ Department of Learning, Informatics, Management and Ethics, Procome Research

Group, Medical Management Centre, Karolinska Institutet, Stockholm, Sweden

${ }^{2}$ Unit for Implementation and Evaluation, Centre for Epidemiology and Community Medicine (CES), Stockholm County Council, Stockholm, Sweden

${ }^{3}$ School of Health, Care and Social Welfare, Mälardalen University, Västerås, Sweden

Correspondence to

Rebecca Mosson;

rebecca.mosson@ki.se

\section{ABSTRACT}

Objectives This study aims to describe the creation of a scale - the iLead scale - through adaptations of existing domain-specific scales that measure active and passive implementation leadership, and to describe the psychometric properties of this scale.

Methods Data collected from a leadership intervention were used in this validation study. Respondents were 336 healthcare professionals $(90 \%$ female and $10 \%$ male; mean age 47 years) whose first-line and secondline managers participated in the intervention. The data were collected in the Stockholm regional healthcare organisation that offer primary, psychiatric, rehabilitation and acute hospital care, among other areas. The items for measuring implementation leadership were based on existent research and the full-range leadership model. Confirmatory factor analysis was performed to evaluate the dimensionality of the scale, followed by tests for reliability and convergent, discriminant and criterionrelated validity using correlations and multilevel regression analyses.

Results The final scale consists of 16 items clustered into four subscales representing active implementation leadership, and one scale signifying passive implementation leadership. Findings showed that the hypothesised model had an acceptable model fit $\left(\chi_{(99)}^{2}=382.864^{\star \star}\right.$, Comparative Fit Index=0.935, Tucker-Lewis Index $=0.911$, root mean square error of approximation $=0.059$ ). The internal consistency and convergent, discriminant and criterion-related validity were all satisfactory.

Conclusions The iLead scale is a valid measure of implementation leadership and is a tool for understanding how active and passive leader behaviours influence an implementation process. This brief scale may be particularly valuable to apply in training focusing on facilitating implementation, and in evaluating leader training. Moreover, the scale can be useful in evaluating various leader behaviours associated with implementation success or failure.

\section{INTRODUCTION}

Implementing change in healthcare is a complex and challenging task. ${ }^{12}$ Nonetheless, this effort is essential for keeping healthcare
Strengths and limitations of this study

The present study follows a rigorous validation process to explore the factor structure, reliability and validity of the iLead scale.

- Since the iLead scale is based on theory and other established scales, confirmatory factor analysis was performed to confirm its suggested factor structure.

- Based on sample characteristics, the sample used for the validation represents a typical healthcare sample.

- Due to item deletion during the validation process, the different subscales in the iLead scale include varying numbers of items.

- The response rate was moderate for the iLead scale, due to the use of a filter variable that assured that only respondents who could remember a specific implementation that their manager had led during the past 6 months were asked to respond to the iLead scale.

professionals up to date on, and ensuring their use of new research evidence so patients can receive the best possible care. Researchers have identified a wide range of contextual factors that influence effective implementation, ${ }^{3-5}$ one of which is leadership. ${ }^{6-8}$

Managers' behaviours during an implementation are crucial for effectively achieving change in practice. This is particularly true for line managers (ie, those with a managerial position closest to employees) who have a direct influence on employees' implementation behaviours. ${ }^{910}$ Research has recognised leadership behaviours such as being supportive, providing feedback, communicating clearly, being a role model, encouraging employee development and creating a context conforming to the implementation as essential in the implementation process (ie, from needs assessment, preparation, implementation and to sustainability of the implementation $\left.^{11}\right) .^{7} \quad{ }^{12-14}$ Moreover, managerial 
tasks, for instance, planning, supervising change and providing resources, are also crucial to support implementation of change. ${ }^{15}$ Both these type of relation and task-related behaviours are central to influence change, ${ }^{16-18}$ and although some scholars make distinctions between managerial and leadership behaviours, others recognise that these behaviours sometimes overlap. ${ }^{19-21}$ This paper does not emphasise a distinction between managerial and leadership behaviours, but view both as complementary processes influencing a group of individuals that are essential for successful change. ${ }^{18} 21$ The scale validated in this study focuses on capturing line managers' implementation-specific leader behaviours-both what they do and how these actions are performed-based on the active and passive dimensions of the full-range leadership model (FRLM). The theoretical perspective is expected to facilitate the understanding of both what managers do (eg, provide information about the implementation) and how these actions are performed (eg, if the information is provided in a way that inspires employees), thereby explaining the relationship between leadership and implementation outcomes.

\section{The full-range leadership model}

The FRLM is the most comprehensively researched approach to leadership. ${ }^{22-25}$ The model clusters leader behaviours into two broad dimensions signifying active and passive leadership. ${ }^{25-28}$ Transformational leadership is one factor of active leadership ${ }^{25} 28$ and is associated with beneficial individual and organisational outcomes, ${ }^{29}$ employee performance, ${ }^{30}$ the change process ${ }^{31} 32$ and organisational innovation ${ }^{33}$ in various contexts and cultures. ${ }^{34}$ There is also emerging evidence on the positive relationship between transformational leadership and effective implementation. ${ }^{10}$ For instance, transformational leadership has been strongly related to employees' innovation implementation behaviour ${ }^{35}$ and their commitment to change. ${ }^{36}$ Transformational leaders inspire employees to achieve higher goals and to perform at a higher level than expected. These leader behaviours were originally divided into three subfactors: idealised influence, acting as a role model and building relationships with employees based on trust and respect; individualised consideration, coaching of staff and helping them develop, while conveying empathy for their needs and desires; and intellectual stimulation, encouraging employees to be creative and to challenge assumptions. ${ }^{28}$ Inspirational motivation was later added as another subfactor to transformational leadership. ${ }^{2037}$ This subfactor concerns articulating a clear and compelling vision to employees and motivating them to achieve set goals. ${ }^{37}$ It has been argued that these transformational leadership subfactors are related, however, it has proved problematic to distinguish between them, ${ }^{25}{ }^{37}$ mainly through difficulties in empirically supporting discriminant validity (ie, high intercorrelations). ${ }^{20} 263839$ Consequently, different approaches to conceptualise and measuring transformational leadership have been adopted. Some have measured it as a global construct, ${ }^{33}{ }^{39}$ whereas others have examined all individual subfactors of transformational leadership, ${ }^{40} 41$ and others have used a reduced set of factors. ${ }^{42}$ It has been especially difficult to distinguish between idealised influence and inspirational motivation, both conceptually ${ }^{2543}$ and empirically. ${ }^{263744}$ Thus, some have combined idealised influence and inspirational motivation into one subfactor. ${ }^{20} 29374445$

Another dimension of active leadership is contingent reward. ${ }^{26}{ }^{28}$ This subfactor is the most active form of transactional leadership and involves an exchange relationship between manager and employees, for instance, setting mutually agreed-upon goals, and follow-up and linking them to rewards. Contingent reward behaviours have been linked to employees' performance outcomes ${ }^{30}$ and satisfaction. ${ }^{26}$ Current suggestions are that a combination of transformational leadership and contingent reward is most effective in producing positive organisational outcomes. ${ }^{23} 30374346$ Based on this, contingent reward is likely to be an important component of active implementation leadership.

Passive leadership includes two dimensions. ${ }^{25} 2728$ One of these is passive management-by-exception, a subfactor of transactional leadership. ${ }^{27}$ This refers to managerial behaviours related to acting first when something has gone wrong, or correcting employee actions when these have been brought to their attention. This subfactorhas shown to be ineffective in achieving organisational outcomes, such as safety at work, ${ }^{27}$ and to negatively impact performance. ${ }^{30}$ The other passive leadership dimension is laissez-faire leadership, where leaders abdicate responsibility and avoid taking initiative, ${ }^{25}$ which has also shown to be ineffective for achieving positive outcomes, ${ }^{23} 27$ and is an overall destructive leader behaviour. ${ }^{48}$ Passive management-by-exception and laissez-faire leadership have been combined in previous studies to represent a generalised passive leadership construct. ${ }^{25} 2747$ These behaviours are typically highly correlated with each other and related to negative employee and organisational outcomes, and negatively associated with active leadership.

An additional subfactor of the transactional leadership construct is active management-by-exception. ${ }^{47}$ This type of leader behaviour is characterised in terms of monitoring for and detecting mistakes that deviate from the norm, and taking corrective action when errors occur. $^{20}{ }^{25}$ There is an ongoing discussion as to whether active management-by-exception fits into the passive or the active categories of leadership ${ }^{47}$ or should be represented separately. ${ }^{46}$ Some have shown that active and passive management-by-exception are separate constructs that are either uncorrelated, or somewhat negatively correlated. ${ }^{25} 47$ Comparing active management-by-exception to the active leadership dimensions, it is more reactive than proactive and cannot be considered an effective leadership style. Therefore, active management-by-exception was not included in this study.

To date, leadership research has mostly focused on measuring active leader behaviours to identify which 
ones are effective and positively influence organisational outcomes. However, capturing passive leader behaviours that negatively influence employees is also of great importance, as these can have disastrous consequences ${ }^{2748} 49$ and will most likely influence the implementation process. The research on implementation leadership has hitherto emphasised behaviours that are effective for implementing change, naturally, since these are needed to achieve implementation success. Nevertheless, it is also important to consider and measure leader behaviours that may be disruptive to, and hinder, an implementation process. This is important, since the way managers lead an implementation can influence the implementation climate both positively and negatively. ${ }^{27} 50$ Implementation climate involves employees' shared perceptions of an implementation initiative's practical value. ${ }^{51}$ Research has demonstrated the relevance of implementation climate for the association between transformational leadership and employees' commitment to change. ${ }^{35}$ Moreover, active leadership may also promote a positive implementation climate, ${ }^{52}{ }^{53}$ and thus influence implementation success. This highlights the importance of capturing both the active and passive aspects of leadership. ${ }^{25} 27$

\section{Implementation-specific leadership}

Recent research on leadership has indicated that leader behaviours directed at a particular initiative or objective, often referred to as domain-specific leadership, ${ }^{275455}$ appear to be more effective than general leader behaviours for reaching the goals of this initiative. Consequently, general active leader behaviours do not seem to be sufficient for affecting a specific domain. In the areas of occupational safety, ${ }^{56}$ employee health and well-being ${ }^{57}$ and service climate, ${ }^{55}$ this has led to the development of domain-specific scales. Several of these scales build on the theory of the FRLM, however, specifically ask the rater to consider leader behaviours in relation to a specific domain. When implementing changes in the healthcare context, this might mean that leader behaviours directed at a specific implementation initiative might be necessary for the success of the implementation process, rather than expecting general active leadership to have an impact. Hence, general leadership may foster a good work environment and performance overall, but may be insufficient for fostering implementation success for a specific evidence-based method to improve the delivery of healthcare. It is therefore necessary to measure leader behaviours specific to an implementation process. This also means that although there is a variety of theory-based scales that measure general leadership, ${ }^{21}$ these may not effectively predict the outcomes of an implementation process. ${ }^{58} 59$

To date, there is one implementation-specific leadership scale: the Implementation Leadership Scale (ILS) ${ }^{60}$ measures strategic leadership in the implementation of evidence-based practices (EBPs) and assesses active leader behaviours that promote implementation of EBPs. ${ }^{60}$ We argue for three main reasons to construct a new scale to measure implementation leadership. First, no scale currently exists that measures active and passive leader behaviours in relation to implementation. This is an important aspect to be included in an implementation leadership scale since passive leader behaviours can have detrimental effects on employees, ${ }^{27}{ }^{30}$ and consequently also for an implementation process. Second, although Aarons and colleagues considered the active leader behaviours of the FRLM when developing the ILS, ${ }^{60}$ the aim was to assess independent and different aspects of implementation leadership. Thus, at present, no scale exists that measures implementation leadership that operationalise the FRLM theory. We suggest that a scale measuring implementation leadership and maintains the FRLM structure is important for obtaining more detailed information about leader behaviours. ${ }^{41}$ Third, the ILS focuses on what managers do when leading implementation (eg, developing a plan to facilitate the process) rather than how it is done (eg, whether these tasks have been performed in a way that inspires employees). We suggest that an implementation leadership scale that, in addition to measuring what, measures how managers lead implementation is valuable for managers in their development as an implementation leader.

In conclusion, the aim of this study is to adapt previous domain-specific scales ${ }^{2761}$ to create and validate a scale that captures managers active and passive implementation-specific leadership behaviours, which follows the factor structure of the FRLM. The objective of the iLead scale is to complement a previous implementation leadership scale (ie, the ILS) by capturing both effective and disruptive implementation leader behaviours by basing the scale on the active and passive dimensions of the FRLM, and to capture what leaders do in addition to how they perform these behaviours. Four subscales are predicted for active implementation leadership and one subscale for passive implementation leadership.

\section{METHODS \\ Adapting previous domain-specific scales to construct the iLead scale}

As a first step, a literature search was performed to identify key research relating to implementation leadership, including previously validated scales. This informed the decision that the scale should follow the factor structure of the FRLM, thus including both active and passive leader behaviours, and be adapted from existing scales. The basis for the construction of the iLead scale was two validated domain-specific leadership scales. ${ }^{27}{ }^{54} \mathrm{We}$ adapted the items from the scale developed by Kelloway et $a l,{ }^{27}$ which measures transformational and passive safety leadership and follows the factor structure of the FRLM, to be implementation specific. For instance, the original item 'My manager shows determination to maintain a safe work environment' was adapted to 'My manager has shown determination to maintain the implementation of the new working method.' We complemented this with 
the subscale 'line managers' attitudes and actions' from the Intervention Process Measure by Randall et al. ${ }^{61}$ This scale specifically focuses on managerial behaviours in relation to occupational health interventions and is one of the few widely used scales attempting to tap into leader behaviours that occur in conjunction with a specific health intervention. The items were adapted slightly to be applicable to the implementation area. This process resulted in a 20-item scale assessing implementation-specific leadership.

The iLead scale was developed as a tool to provide feedback for managers on their leader behaviours. This scale was applied in an implementation leadership training intervention that aims to train healthcare managers implementation leadership (the iLead intervention-please see the study protocol for further details of this intervention ${ }^{62}$ ), referred to as the 'intervention' throughout this study. It was therefore important that the scale could distinguish between different types of active and passive leader behaviours, as previously suggested. ${ }^{38}{ }^{41}$ Hence, a differentiation between the factors was sought. Although idealised influence and inspirational motivation may be argued to be conceptually different, ${ }^{37} 43$ studies have not been able to consistently empirically separate these subfactors. ${ }^{37} 45$ Therefore, idealised influence and inspirational motivation were combined and called exemplary behaviours, which is in line with previous studies using the FRLM. ${ }^{204244}$ Consequently, the iLead scale measures active implementation leadership, from here on referred to as active leadership, through four subscales-the exemplary behaviours (seven items), individualised consideration (three items), intellectual stimulation (five items) and contingent reward (two items). Passive implementation leadership, from here on referred to as passive leadership, comprises elements from both passive management-by-exception and laissez-faire leader behaviours (three items), in line with a previous scale measuring domain-specific leadership. ${ }^{19}$

\section{Assurance of content validity}

In addition to basing the iLead items on existing scales, two additional approaches were used to assure content validity. ${ }^{63}$ National experts in the field of leadership and implementation $(n=5)$ and managers in a healthcare organisation $(n=40)$ were invited to a workshop to identify crucial implementation leader behaviours. This was performed using a structured and interactive processthe co-created programme logic. ${ }^{64}$ The first step was to individually brainstorm leader behaviours perceived as important in implementation, which were written on post-it notes. Thereafter, these notes with different leader behaviours were attached to a whiteboard and the participants discussed these behaviours together in groups and categorised them into overall themes. Examples of themes were: 'inspire and motivate employees' and 'be responsive to employees' needs'. The themes that emerged during this process were in line with scientific literature on effective leader behaviours when implementing change. Third, to test the face validity of the scale, ${ }^{63}$ employees and senior managers $(n=11)$ representing the healthcare organisations completed a draft of the questionnaire and were asked for oral feedback on whether the items were clearly formulated, relevant and understandable, and if they perceived that the scale measured the construct it aimed to measure. This did not lead to any major changes to the items.

\section{Participants}

The data for the present study were collected as part of an implementation leadership training intervention that was developed and evaluated in the Stockholm regional healthcare organisation. ${ }^{62}$ This organisation offers primary, psychiatric, rehabilitation and acute hospital care, among other areas. The data used in the present study originate from the baseline measurement (time 1), conducted in November/December 2015, with the exception of one scale collected from the first follow-up (time 2) in May/June 2016 to assess predictive criterion validity. All employees whose managers were taking part in the iLead intervention and who were not on leave of absence, parental leave, had quit their job, etc were invited to participate in the study. Employee data were used since managers' self-ratings are often inflated due to leniency bias, ${ }^{6566}$ and previous studies have demonstrated the validity of using employees' assessments of leader behaviours. ${ }^{67} 68$ Out of 1084 eligible healthcare professionals, 815 responded ( $75 \%$ response rate) to the baseline measurement (time 1). Of these, 336 respondents $(41 \%)$ answered the iLead scale. This was because a filter was included at the beginning of the questionnaire to ensure that only respondents who could remember a specific implementation responded to questions about their manager's implementation leadership. They were instructed to replace the phrase 'the new working method' in each question of the iLead scale with the implementation they had identified in the filter question.

The follow-up measurement was performed immediately after the implementation leadership training intervention (time 2), ${ }^{62} 6$ months after the baseline measurement. The purpose of using data at time 2 was to assess the predictive type of criterion validity (ie, using a criterion that occurs in the future) ${ }^{63}$ Thus, data on implementation climate were used since active leadership is an important predictor of a positive implementation climate.$^{5153} \mathrm{~A}$ total of 490 respondents answered the questionnaire at time 2, and $443(90 \%)$ of these answered all the implementation climate items.

The majority of respondents were female $(90 \%)$ and had worked at their current job for 2-5years (26.8\%). All the managers were female. The high number of females is representative of the healthcare context in Sweden. ${ }^{69}$ The participants' mean age was 47 years $(\mathrm{SD}=11.8$; range: 22-65). Most participants, $79.6 \%$ had obtained a university degree; $18.7 \%$ had finished high school and $1.7 \%$ had no further education, that is, lower than a high school education. 


\section{Procedure}

The respondents received a secured link to an electronic questionnaire through their work email, including information about the study and the purpose of the questionnaire. Two reminders were sent, with a 2-week time interval. All participants provided informed consent that their data could be used in research, and confirmed that they understood that participation was voluntary and that they could withdraw their participation at any time.

\section{Patient and public involvement}

Important stakeholders (national experts, line managers and employees) were involved in this study as described above (see assurance of content validity). Patient's involvement was not applicable in this study.

\section{Measures}

Implementation-specific active and passive leadership was measured through the iLead scale (described under the section 'Adapting previous domain-specific scales to construct the iLead scale'). All 20 items were scored on a 1 (strongly disagree) to 5 (strongly agree) Likert scale.

\section{Convergent and discriminant validity measures}

General transformational leadership was measured through the Global Transformational Leadership scale ${ }^{39}$ using seven items. An example item is: 'My closest manager communicates a clear and positive vision of the future.' Items were scored on a 1 (strongly disagree) to 5 (strongly agree) Likert scale. Cronbach's alpha was 0.95 .

General transactional leadership was measured through two items used in previous research that are based on the Multifactor Leadership Questionnaire, modified to be implementation specific. ${ }^{2527}$ The items focus on contingent reward behaviours, for example: 'My manager shows satisfaction when employees meet expectations.' Items were scored on a 1 (strongly disagree) to 5 (strongly agree) Likert scale. Cronbach's alpha was 0.81.

\section{Criterion-related validity measure}

Implementation climate was measured with three items derived from the subscale 'Focus on EBP' of the Implementation Climate Scale ${ }^{51}$ (collected at time 2). These items were deemed relevant for assessing implementation climate due to their specific nature, and were therefore adapted to the present study. For example, 'Using EBPs is a top priority in this team/agency' was changed to 'At my workplace it is a top priority to change our working methods in order to achieve the best possible quality.' Items were scored on a 1 (strongly disagree) to 5 (strongly agree) Likert scale. Cronbach's alpha was 0.86.

\section{Statistical analyses}

Two major approaches were used to validate the scale. ${ }^{63}$ Its dimensionality was evaluated through confirmatory factor analysis (CFA) using AMOS V.23. CFA was chosen over an exploratory factor analysis (EFA) since the factor structure of the implementation-specific scale (ie, FRLM) is well established in the literature and has prior validity evidence. ${ }^{20} 267071$ This is also in line with previous studies of domain-specific scales based on the FRLM. ${ }^{27}$ Thus, CFA is used to deductively confirm that the data in the present study fit into the already proposed factor structure, whereas an EFA is more inductive in its approach and should be used when developing new scales with items that have not been tested in terms of reliability and validity. ${ }^{72}$ The maximum likelihood (ML) estimation approach was used to address missing data values. ${ }^{73}$ One path indicator for each latent variable was fixed to set the scale of the latent variable. Model fit was assessed using several fit indices, including the $\chi^{2}$, the Comparative Fit Index (CFI), the Tucker-Lewis Index (TLI) and the root mean square error of approximation (RMSEA).$^{7374}$ The following approximate cut-off criteria were used, whereby CFI and TLI around $0.90^{73}$ and an RMSEA value of $\leq 0.06^{74}$ indicate a good fit to the data. ${ }^{75}$ Information criteria such as the Akaike information criterion and the $\chi^{2}$ difference test were used for model comparison, whereby a model with a lower value indicates a more acceptable model fit. ${ }^{73}$

First, item characteristics, such as comments from participants or factor loadings, were considered to identify items for exclusion. Following this, five competing models were compared to test the hypothesised factor structure of the scale. ${ }^{73}{ }^{76}$ In line with previous research, a second-order factor model is proposed for the active implementation leadership factors due to high factor correlations. ${ }^{253944}$ The $\chi^{2}$ difference test was used to identify the best-fitting model. Moreover, additional rigorous tests were performed by analysing a bifactor model to partition the variance of the multidimensional scales. Findings from the bifactor model were in line with the results from the CFA.

Second, the reliability of each subscale was assessed via internal consistency (Cronbach's alpha). ${ }^{63}$ Convergent validity of implementation leadership was then analysed. Here, our scale was correlated with theoretically similar instruments, ${ }^{63} 76$ such as general transformational ${ }^{39}$ and transactional leadership. ${ }^{25}$ Correlations should be higher than $0.40 .^{77}$ Discriminant validity was tested through the correlation of passive implementation leadership with general transformational and transactional leadership. For this, passive leadership was correlated with two constructs to which it should be negatively related. ${ }^{63}$ Lastly, the criterion-related validity ${ }^{63} 76$ was examined by performing regression models with implementation climate at time 2 as the outcome, which is a theoretical outcome of implementation leadership. ${ }^{52} 53$ Multilevel modelling was used to account for the nestedness of the data (employees nested in workgroups) using Mplus V.7.2 and ML estimation. ${ }^{78}$ All predicators were grand-mean centred before being entered in the model. ${ }^{79}$ We expect a positive relation between active leadership at time 1 and implementation climate at time 2 when age, gender and education are controlled for. 
Table 1 Model comparisons

\begin{tabular}{|c|c|c|c|c|c|c|c|c|c|}
\hline Models & $\chi^{2}$ & df & CFI & TLI & RMSEA & AIC & $\begin{array}{l}\text { Model } \\
\text { comparison }\end{array}$ & $\Delta \mathrm{df}$ & $\Delta \chi^{2}$ \\
\hline Model 1 & $382.864^{* *}$ & 99 & 0.935 & 0.911 & 0.059 & 488.864 & & & \\
\hline Model 2 & $388.906^{\star *}$ & 100 & 0.934 & 0.911 & 0.060 & 492.906 & 1 vs 2 & 1 & $6.04^{*}$ \\
\hline Model 3 & $452.720^{\star \star}$ & 101 & 0.920 & 0.892 & 0.065 & 554.720 & 2 vs 3 & 1 & $63.81^{\star \star}$ \\
\hline Model 4 & $501.158^{\star \star}$ & 103 & 0.909 & 0.880 & 0.069 & 599.158 & 3 vs 4 & 2 & $48.44^{\star \star}$ \\
\hline Model 5 & $1655.889^{* *}$ & 170 & 0.740 & 0.678 & 0.104 & 1775.889 & 4 vs 5 & 67 & $1154.73^{\star \star}$ \\
\hline
\end{tabular}

$\mathrm{n}=336 .{ }^{*} \mathrm{P}<0.05 ;{ }^{* \star} \mathrm{P}<0.01$. CFI, Comparative Fit Index; TLI, Tucker-Lewis Index; RMSEA, Root Mean Square Error of Approximation ; AIC, Akaike Information Criterion .

Model 1: exemplary behaviours (EB), individualised consideration (IC), intellectual stimulation (IS) and contingent reward (CR) were included as four first-order factors under one second-order factor for active leadership (AL), and passive leadership (PL) was intercorrelated with AL. Model 2: IC and IS were collapsed into one factor, resulting in three first-order factors for the AL second-order factor and PL was intercorrelated with AL.

Model 3: EB, IC and IS were collapsed into one factor, resulting in two first-order factors for the AL second-order factor, and PL was intercorrelated with AL.

Model 4: all the active factors (transformational leadership subfactors and CR) were collapsed into one first-order factor, and PL was intercorrelated with AL.

Model 5: all items loaded on one single factor.

These relations were modelled on the individual level (level 1).

\section{Results}

Examination of items and dimensionality

Initial examination of the items when conducting the CFA resulted in the removal of 4 of the 20 items. These items either did not capture the intended construct (factor loading $<0.4$ ) or had low correlations $(r \leq 0.3)$ with other items of the same construct, ${ }^{80}$ and one of them was excluded due to participants commenting that it was difficult to understand, and thus to answer. Consequently, 16 items were included for all further calculations.

To investigate the dimensionality of the scale (ie, whether the subscales can be separated from each other), five competing models were compared. Description of the models and findings from these model comparisons are presented in table 1 . The results from the CFA showed that model 1, our hypothesised model with four active implementation leadership subscales, was the best-fitting model. That is, models $2-5$ fit the data significantly worse than model 1, which had an acceptable model fit $\left(\chi_{(99)}^{2}{ }^{=} 382.864 * *, \mathrm{CFI}=0.935\right.$, TLI=0.911, RMSEA=0.059). Figure 1 displays the standardised factor loadings of this model.

Hence, the final scale includes 16 items representing four active leadership subscales (ie, exemplary behaviours (six items), individualised consideration (two items), intellectual stimulation (three items) and contingent reward (two items) and passive leadership (three items). Internal consistency was considered satisfactory for all subscales $(\alpha>0.70) .{ }^{63}$ The final iLead scale, its constituent items and internal consistency of the subscales are presented in table 2.

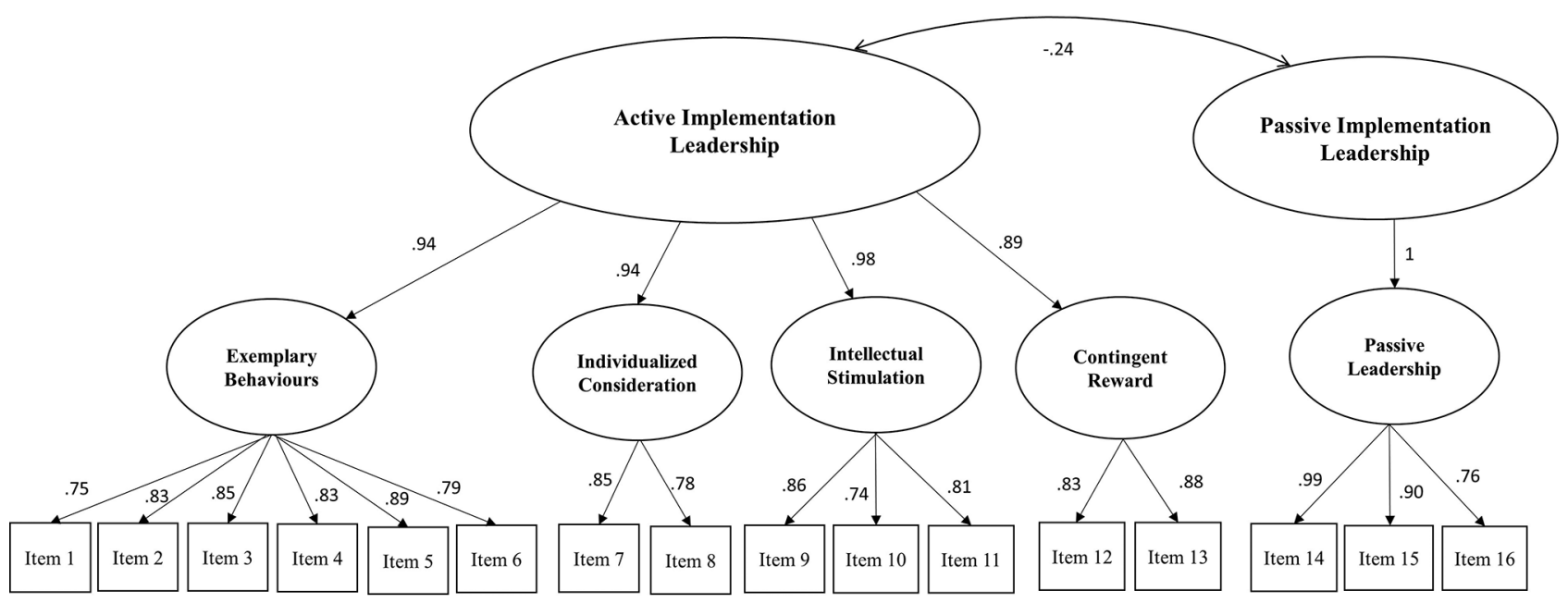

Figure 1 Standardised factor loadings for the iLead scale. $n=336$; All confirmatory factor analysis factor loadings are for model $1\left(\chi_{(99)}^{2}=382.864^{\star \star}, \mathrm{CFI}=0.935, \mathrm{TLI}=0.911, \mathrm{RMSEA}=0.059\right)$ with four first-order factors under one second-order factor for active implementation leadership, which is intercorrelated with a passive implementation leadership factor. 


\begin{tabular}{|c|c|c|}
\hline Scales and constituent items & $\alpha$ & $\begin{array}{l}\text { Item } \\
\text { no }\end{array}$ \\
\hline 1. Active implementation leadership & 0.95 & \\
\hline $\begin{array}{l}\text { 1a. Exemplary behaviours } \\
\text { My closest manager... }\end{array}$ & 0.92 & \\
\hline $\begin{array}{l}\text {...has shown determination to } \\
\text { maintain the new working method }\end{array}$ & & 1 \\
\hline $\begin{array}{l}\text {...has talked about his/her values and } \\
\text { beliefs of why it is important to work } \\
\text { according to the new working method }\end{array}$ & & 2 \\
\hline $\begin{array}{l}\text {...has actively worked towards } \\
\text { implementing the new working } \\
\text { method }\end{array}$ & & 3 \\
\hline $\begin{array}{l}\text {...has continuously encouraged us } \\
\text { in the implementation of the new } \\
\text { working method }\end{array}$ & & 4 \\
\hline
\end{tabular}

...has behaved in a way that explicitly

displays commitment to working according to the new working method

...has been positive towards the implementation of the new working method

1b. Individualised consideration

My closest manager...

...has spent time showing me how

I can work according to the new working method

...has given me the opportunity to speak to him/her about what consequences the implementation of the new working method will have for me

1c. Intellectual stimulation

0.83

My closest manager...

...has done a lot to involve us in the implementation of the new working method

...has encouraged me to express

0.80

my ideas and opinions about

implementing the new working method

...has shared whatever information he/

she has about the implementation of the new working method

1d. Contingent reward

My closest manager...

...has shown satisfaction when I work according to the new working method

...has shown appreciation when we have achieved our goals to implement the new working method at our workplace
Table 2 Continued

\begin{tabular}{|lll|} 
Scales and constituent items & $\boldsymbol{\alpha}$ & $\begin{array}{l}\text { Item } \\
\text { no }\end{array}$ \\
\hline 2. Passive implementation leadership & 0.91 & \\
\hline
\end{tabular}

My closest manager...

...has avoided to intervene until major problems with the implementation of the new working method have arisen

...has waited for things to go wrong

with the implementation of the new working method before taking any action

...has avoided making decisions that affect the implementation of the new working method

$\mathrm{n}=324-336$, due to missing data on some items (pairwise deletion).

\section{Convergent and discriminant validity}

Bivariate correlations of all the measures in the present study and descriptive statistics are presented in table 3. To assess convergent validity, the correlations between active leadership and general transformational and transactional leadership were calculated. Correlations between the subfactors of active and general transformational leadership $\left(\mathrm{r}=0.70-0.78^{* *}\right)$ and transactional leadership $\left(\mathrm{r}=0.61-0.70^{* *}\right)$ were high, supporting convergent validity. To assess discriminant validity, the correlations between passive leadership and general transformational and transactional leadership were calculated, showing a correlation of $\mathrm{r}=-0.22 * *$ with general transformational leadership and a correlation of $\mathrm{r}=-0.18^{* *}$ with transactional leadership. These results support discriminant validity.

\section{Criterion-related validity}

Criterion-related validity was tested by examining the relationship between implementation climate (measured at time 2) and active and passive leadership at time 1. In line with expectations, findings show that when age, gender and education were controlled for, active leadership significantly predicted implementation climate $\left(\mathrm{B}=0.40^{*}\right)$. A slight negative relation that was not statistically significant $(\mathrm{B}=-0.07)$ was observed between passive leadership and implementation climate (table 4).

\section{DISCUSSION}

The aim of the present study was to adapt previous domain-specific scales to create and validate an active and passive implementation-specific leadership scale that follows the factor structure of the FRLM-the iLead scale. The analyses supported good psychometric properties for the scale. Thus, the iLead scale can be used to assess how managers lead an implementation. This scale complements the knowledge about what leaders do and meets the need for a scale linking implementation leadership 


\begin{tabular}{|c|c|c|c|c|c|c|c|c|c|}
\hline Scales & Mean & SD & $1 a$ & $1 b$ & 1c & 1d & 2 & 3 & 4 \\
\hline 1. Active implementation leadership & 3.84 & 0.88 & & & & & & & \\
\hline 1a. Exemplary behaviours & 4.06 & 0.86 & & & & & & & \\
\hline 1b. Individualised consideration & 3.60 & 1.10 & $0.73^{\star \star}$ & & & & & & \\
\hline 1c. Intellectual stimulation & 3.87 & 0.93 & $0.87^{\star \star}$ & $0.84^{\star \star}$ & & & & & \\
\hline 1d. Contingent reward & 3.84 & 0.97 & $0.75^{\star \star}$ & $0.71^{\star *}$ & $0.76^{* *}$ & & & & \\
\hline 2. Passive implementation leadership & 2.01 & 1.17 & $-0.20^{\star \star}$ & $-0.12^{*}$ & $-0.20^{\star *}$ & $-0.17^{\star \star}$ & & & \\
\hline 3. General transformational leadership & 3.87 & 0.93 & $0.77^{\star \star}$ & $0.70^{\star *}$ & $0.78^{* *}$ & $0.70^{* *}$ & $-0.22^{\star *}$ & & \\
\hline 4. General transactional leadership & 3.79 & 0.97 & $0.68^{\star \star}$ & $0.64^{\star \star}$ & $0.70^{\star \star}$ & $0.61^{\star *}$ & $-0.18^{\star *}$ & $0.86^{\star *}$ & \\
\hline 5. Implementation climate & 3.92 & 0.92 & $0.34^{\star \star}$ & $0.37^{\star \star}$ & $0.27^{\star \star}$ & $0.45^{\star \star}$ & $-0.17^{\star}$ & $0.44^{\star \star}$ & $0.44^{\star \star}$ \\
\hline
\end{tabular}

$\mathrm{n}=158-649$, due to missing data on some items (pairwise deletion). ${ }^{*} \mathrm{P}<0.05,{ }^{\star \star} \mathrm{P}<0.01$.

Data were collected at time 1 for all measures, except for implementation climate, which was collected at time 2.

with theory. This is essential for uncovering how day-to-day leadership affects the implementation process.

The predicted four subscales for active leadership and the scale for passive leadership were confirmed through CFA. Thus, analysis supports the existence of two distinct dimensions: active and passive leadership. As specified, active leadership was differentiated into four subfactors: exemplary behaviours, intellectual stimulation, individualised consideration and contingent reward with a common second-order factor representing active leadership. This indicates that even though different subfactors could be distinguished, they were all highly related, as captured in the second-order factor (ie, active leadership). This is in line with previous studies in which a second-order factor has been used to capture the correlation between the subfactors. ${ }^{263944}$ These findings were also confirmed by the bifactor model. This analysis showed that the common factor of active leadership explained a large part of the variance, with a unique contribution of each of the four subscales. Similar to other theoretical constructs (eg, intelligence or self-rated productivity), this means that each subscale reflects the common factor of active leadership to a larger extent than it reflects the subscales and should not be analysed independently without the common factor (see online supplementary

Table 4 Multilevel regressions: implementation climate regressed on age, gender, education and active and passive implementation leadership

\begin{tabular}{lcc}
\hline & Model 1 & Model 2 \\
\cline { 2 - 2 } Predictor variables & B (SE) & B (SE) \\
\hline Age & $0.009^{*}(0.004)$ & $-0.01^{*}(0.01)$ \\
Gender (women) & $0.14(0.15)$ & $0.07(0.16)$ \\
University education & $-0.10(0.15)$ & $0.06(0.17)$ \\
$\begin{array}{l}\text { Active implementation } \\
\text { leadership }\end{array}$ & $0.40^{*}(0.08)$ \\
$\begin{array}{l}\text { Passive implementation } \\
\text { leadership }\end{array}$ & $-0.07(0.05)$ \\
\hline
\end{tabular}

${ }^{*} \mathrm{P}<0.05$; Intraclass correlations $(\mathrm{ICC})=0.15$. appendix). Nevertheless, since each subfactor contributes with unique variance, they should still be distinguished in the model, and they can be used in the context of providing actionable feedback to managers in leadership training. ${ }^{25441}$ In this context, the level of detail provided through the subscales help distinguish which specific subtype of leader behaviours that need to improve. Thus, the iLead scale can be used in implementation training, for example, to provide leaders with feedback and to evaluate the training, in addition to the research context.

As anticipated, findings demonstrated that the passive leadership dimension is empirically distinct from, although correlated with, the active one. This indicates that having a scale that represents the continuum of leader behaviours in the same structural model is feasible for capturing both effective and ineffective leader behaviours. In the present study, passive management-by-exception and laissez-faire items represent the passive domain, considering their ineffective styles. ${ }^{25} 27$ To date, most research has focused on active leader behaviours, ${ }^{22}{ }^{23}$ despite the fact that both active and passive leader behaviours influence employees and organisational outcomes. ${ }^{25} 2730$ However, the importance of also considering passive leader behaviours is receiving more research attention. ${ }^{27}{ }^{28}$ For instance, a study investigating the impact of safety-specific transformational and passive leadership on safety outcomes demonstrated that the safety-specific passive leader behaviours had a negative effect on outcomes (ie, increased injury). ${ }^{27}$ Thus far, implementation research has not focused on assessing ineffective leader behaviours or investigated their influence on an implementation process. Through the creation of the iLead scale, there is now an approach to assess active, and passive leadership within the implementation context. This is an important next step, since passive behaviours may actually have a negative impact when implementing change. The present study thereby adds to existing knowledge of the overall effect of leadership on the implementation process. Consequently, the iLead scale complements the existing scale measuring 
implementation leadership (ie, the ILS), which focuses on measuring active implementation leadership.

The validity of the iLead scale was evaluated by investigating how it relates to other measurements. ${ }^{6376}$ Findings confirmed expected negative relations between the passive leadership and general transformational ${ }^{39}$ and transactional leadership. ${ }^{25}$ Moreover, the expected positive relations between active implementation leadership with the general leadership scales were confirmed with moderate-to-high correlations. This indicates that these measures belong to a similar latent construct, but that the iLead scale also captures certain unique aspects of leadership. Furthermore, active leadership predicted a higher implementation climate over time, whereas passive leadership was not significantly associated with implementation climate. This finding contradicts previous research that has found a negative correlation with passive leadership and specific climate. ${ }^{27}$ Thus, this should be further explored in future studies. That active leadership predicts implementation climate is in line with implementation frameworks summarising the process of implementation, for instance, the Exploration, Preparation, Implementation and Sustainment (EPIS) model. ${ }^{81}$ According to EPIS, active leadership should ultimately result in a favourable climate at the workplace, with employees perceiving implementation as part of the daily routine. These predictions have been confirmed in several empirical studies. ${ }^{50} 82$

A methodological aspect worth mentioning is that only those employees who could remember a specific implementation effort conducted at their workplace during the past 6 months were asked to respond to the iLead scale. Therefore, only $41 \%$ of the 815 eligible respondents answered the iLead scale. This aspect is perceived as informative, since leadership research has previously been criticised for assuming that employees have actually witnessed, and can therefore rate, the behaviour of their manager, which is not always the case ${ }^{83}$ Thus, to be particularly restrictive in evaluating this new measure, a filter variable was included in the questionnaire to ensure that employees actually had valid knowledge of their manager's implementation leader behaviour. It may be argued that those who answered these questions were those who could make a proper judgement about their manager's implementation leadership. The sample size was nonetheless still sufficient, as there were at least 10 times more raters than questionnaire items in the analyses. ${ }^{73}$

The scale did not include active management-by-exception from the FRLM, which is described as the leader looking for mistakes and enforcing rules to avoid these mistakes. ${ }^{25}$ This was a result of certain problems associated with this construct. For instance, the operationalisation of active management-by-exception is specifically troublesome since it often focuses only on negative control behaviours, such as stopping behaviours. ${ }^{56}$ This is despite the fact that it theoretically also includes positive control behaviours, such as monitoring and enforcing policies and routines, which show that the specific objective (eg, implementation or safety) is an enacted priority. ${ }^{56}$ Moreover, the reliability of subscales aiming to capture active management-by-exception has been problematic. ${ }^{30}$ Research has also indicated that it is primarily transformational leadership and contingent reward that result in positive effects. ${ }^{25} 30$ Consequently, the active management-by-exception factor was excluded from the iLead scale, which only incorporates the FRLM leadership dimensions that can be clearly distinguished into an overall active or passive implementation leadership category. This is in line with previously developed scales. ${ }^{27} 54$

Only three items were included to measure passive leadership. Although it is crucial to capture leader behaviours that may hinder an implementation process (passive leadership), it is even more valuable to capture those that have a positive effect on, and promote successful, implementation (active leadership), especially when using the scale in a leadership intervention as a source of feedback. Moreover, some subfactors are represented by fewer than the recommended three items for new scales. ${ }^{84}$ However, the iLead scale is based on the FRLM and previous domain-specific scales. In addition, there are examples of brief and even single-item scales that have good psychometric properties. ${ }^{63}$ With the healthcare setting in mind when tailoring and creating the iLead scale, the ambition was to make it as pragmatic and feasible as possible to use in practice.$^{85}$ Thus, the iLead scale is a brief, concise and broadly applicable scale that may be used in the daily practice were continuous implementations are performed to improve patient outcomes.

\section{CONCLUSIONS}

This study describes a scale with good psychometric properties for measuring active and passive implementation leadership—the iLead scale. Including these aspects is relevant since both active and passive leader behaviours may influence employees' performance throughout an implementation process. More explicitly, the scale measures both what leaders do as well as how they perform these actions, through exemplary behaviour, individualised consideration, intellectual stimulation and contingent reward, and passive behaviours. The iLead scale is based on the most widely applied leadership model, the FRLM, which makes the results relatable to a vast amount of research based on this theory. It also measures implementation-specific leadership in contrast to general leadership. Domain-specific leadership is associated with being more predictive for specific outcomes, such as implementation success, than general leadership. Thus, the iLead scale is a valid tool that can be used to understand how leader behaviours influence implementation success, and may be particularly valuable to apply in training implementation and evaluating leader training.

Acknowledgements The authors would like to extend special thanks to the employees who answered the questionnaire, thus making this study possible. 
Contributors RM, AR, UvTS, HH and RL contributed to the theoretical background and study design. RM, AR, UvTS and HH contributed to the item development. RM performed the data analysis, with contributions from AR. For the present article, RM drafted the first version. All other authors contributed to writing and editing all parts of the article. All authors approved the final version.

Funding This study is part of a project that has received research grant funding from AFA Insurance (project no. 140114) after competitive peer review. AFA Insurance is one of the largest nationally recognised Swedish research agencies funding research on work environment and health.

Disclaimer The funder did not have any role in the design of the project.

Competing interests None declared.

Patient consent Not required.

Ethics approval The regional ethics committee in Stockholm (ref no. 2015/857$31 / 5)$ approved the data collection for the project.

Provenance and peer review Not commissioned; externally peer reviewed.

Data sharing statement This study presents all the items used to measure implementation leadership. Please contact the corresponding author for data requests.

Open access This is an open access article distributed in accordance with the Creative Commons Attribution Non Commercial (CC BY-NC 4.0) license, which permits others to distribute, remix, adapt, build upon this work non-commercially, and license their derivative works on different terms, provided the original work is properly cited and the use is non-commercial. See: http://creativecommons.org/ licenses/by-nc/4.0/

C Article author(s) (or their employer(s) unless otherwise stated in the text of the article) 2018. All rights reserved. No commercial use is permitted unless otherwise expressly granted.

\section{REFERENCES}

1. Grimshaw JM, Eccles MP, Lavis JN, et al. Knowledge translation of research findings. Implement Sci 2012;7:50.

2. Grol R, Grimshaw J. From best evidence to best practice: effective implementation of change in patients' care. Lancet 2003;362:1225-30.

3. Damschroder LJ, Aron DC, Keith RE, et al. Fostering implementation of health services research findings into practice: a consolidated framework for advancing implementation science. Implement Sci 2009;4:50.

4. Squires JE, Graham ID, Hutchinson AM, et al. Identifying the domains of context important to implementation science: a study protocol. Implement Sci 2015;10:135.

5. Rycroft-Malone J. The PARIHS framework--a framework for guiding the implementation of evidence-based practice. J Nurs Care Qual 2004;19:297-304.

6. Greenhalgh T, Robert G, Macfarlane F, et al. Diffusion of innovations in service organizations: systematic review and recommendations. Milbank Q 2004;82:581-629.

7. Ovretveit J. Improvement leaders: what do they and should they do? A summary of a review of research. Qual Saf Health Care 2010;19:490-2.

8. Stetler CB, Ritchie JA, Rycroft-Malone J, et al. Institutionalizing evidence-based practice: an organizational case study using a model of strategic change. Implement Sci 2009;4:78.

9. Birken SA, Lee SY, Weiner BJ. Uncovering middle managers' role in healthcare innovation implementation. Implement Sci 2012;7:28.

10. Aarons GA, Ehrhart MG, Farahnak LR, et al. Leadership and organizational change for implementation (LOCl): a randomized mixed method pilot study of a leadership and organization development intervention for evidence-based practice implementation. Implement Sci 2015;10:11.

11. Fixsen DL, Naoom SF, Blase KA, et al; Implementation Research: $A$ Synthesis of the Literature. Tampa, FL: University of South Florida, Louis de la Parte Florida Mental Health Institute, The National Implementation Research Network (FMHI Publication \#231), 2005.

12. Gifford W, Davies B, Edwards N, et al. Managerial leadership for nurses' use of research evidence: an integrative review of the literature. Worldviews Evid Based Nurs 2007;4:126-45.

13. Reichenpfader U, Carlfjord S, Nilsen P. Leadership in evidencebased practice: a systematic review. Leadersh Health Serv 2015;28:298-316.
14. Avolio BJ, Walumbwa FO, Weber TJ. Leadership: current theories, research, and future directions. Annu Rev Psychol 2009;60:421-49.

15. Battilana J, Gilmartin M, Sengul M, et al. Leadership competencies for implementing planned organizational change. Leadersh $Q$ 2010;21:422-38.

16. Bass BM. From transactional to transformational leadership: Learning to share the vision. Organ Dyn 1990;18:19-31.

17. Nadler DA, Tushman ML. The organization of the future: Strategic imperatives and core competencies for the 21st century. Organ Dyn 1999;28:45-60.

18. Kotter JP. What leaders really do. Harvard Business Review 1990;79:103-11.

19. Zaccaro SJ, Horn ZNJ. Leadership theory and practice: Fostering an effective symbiosis. Leadersh Q 2003;14:769-806.

20. Yukl G. Leadership in Organizations. 6th edn. New Jersey: Pearson Higher Education, 2005.

21. Northouse P. Leadership: Theory and Practice. 5th ed: SAGE Publications, Inc, 2010.

22. Lowe KB, Gardner WL. Ten years of The leadership quarterly: contributions and challenges for the future. Leadersh $Q$ 2000;11:459-514.

23. Judge TA, Piccolo RF. Transformational and transactional leadership: a meta-analytic test of their relative validity. J Appl Psychol 2004;89:755-68.

24. Antonakis J, House RJ. Instrumental leadership: Measurement and extension of transformational-transactional leadership theory. Leadersh Q 2014;25:746-71.

25. Avolio BJ, Bass BM, Jung DI. Re-examining the components of transformational and transactional leadership using the Multifactor Leadership. J Occup Organ Psychol 1999;72:441-62.

26. Bycio P, Hackett RD, Allen JS. Further assessments of Bass's (1985) conceptualization of transactional and transformational leadership. $J$ Appl Psychol 1995;80:468-78.

27. Kelloway EK, Mullen J, Francis L. Divergent effects of transformational and passive leadership on employee safety. $J$ Occup Health Psychol 2006;11:76-86.

28. Bass BM. Leadership and Performance Beyond Expectations. New York: Free Press, 1985.

29. Barling J, Weber T, Kelloway EK. Effects of transformational leadership training on attitudinal and financial outcomes: a field experiment. J Appl Psychol 1996;81:827-32.

30. Bass BM, Avolio BJ, Jung DI, et al. Predicting unit performance by assessing transformational and transactional leadership. J Appl Psychol 2003;88:207-18.

31. Eisenbach R, Watson K, Pillai R. Transformational leadership in the context of organizational change. J of Chang Manag 1999;12:80-9.

32. Holten A-L, Brenner SO. Leadership style and the process of organizational change. Leadership Org Dev J 2015;36:2-16.

33. Jung DI, Chow $\mathrm{C}$, Wu A. The role of transformational leadership in enhancing organizational innovation: Hypotheses and some preliminary findings. Leadersh Q 2003;14:525-44.

34. Den Hartog DN, House RJ, Hanges PJ, et al. Culture specific and cross-culturally generalizable implicit leadership theories: Are attributes of charismatic/transformational leadership universally endorsed? Leadership Q 1999;10:219-56.

35. Michaelis B, Stegmaier R, Sonntag K. Shedding light on followers' innovation implementation behavior. J Manage Psychol 2010;25:408-29.

36. Herold DM, Fedor DB, Caldwell S, et al. The effects of transformational and change leadership on employees' commitment to a change: a multilevel study. J Appl Psychol 2008;93:346-57.

37. Barbuto JE. Motivation and transactional, charismatic, and transformational leadership: a test of antecedents. JLOS 2005;11:26-40.

38. Hardy L, Arthur CA, Jones G, et al. The relationship between transformational leadership behaviors, psychological, and training outcomes in elite military recruits. Leadersh Q 2010;21:20-32.

39. Carless S, Wearing A, Mann L. A short measure of transformational leadership. JBP 2000;14:389-405.

40. Podsakoff PM, MacKenzie SB, Bommer WH. Transformational Leader Behaviors and Substitutes for Leadership as Determinants of Employee Satisfaction, Commitment, Trust, and Organizational Citizenship Behaviors. J Manage 1996;22:259-98.

41. Antonakis J, Avolio BJ, Sivasubramaniam N. Context and leadership an examination of the nine-factor full-range leadership theory using the Multifactor Leadership Questionnaire. Leadersh $Q$ 2003;14:261-95.

42. Larsson $\mathrm{G}$. The Developmental Leadership Questionnaire (DLQ): some psychometric properties. Scand J Psychol 2006;47:253-62.

43. Rafferty AE, Griffin MA. Dimensions of transformational leadership: Conceptual and empirical extensions. Leadersh Q 2004;15:329-54. 
44. Tepper BJ, Percy PM. Structural Validity of the Multifactor Leadership Questionnaire. Educ Psychol Meas 1994;54:734-44.

45. Hinkin TR, Tracey JB. The relevance of charisma for transformational leadership in stable organizations. JOCM 1999;12:105-19.

46. Clarke S. Safety leadership: A meta-analytic review of transformational and transactional leadership styles as antecedents of safety behaviours. J Occup Organ Psychol 2013;86:22-49.

47. Garman AN, Davis-Lenane D, Corrigan PW. Factor structure of the transformational leadership model in human service teams. J Organ Behav 2003;24:803-12.

48. Skogstad A, Einarsen S, Torsheim T, et al. The destructiveness of laissez-faire leadership behavior. J Occup Health Psychol 2007;12:80-92.

49. Dóci E, Stouten J, Hofmans J. The cognitive-behavioral system of leadership: cognitive antecedents of active and passive leadership behaviors. Front Psychol 2015;6:1344.

50. Aarons GA, Ehrhart MG, Farahnak LR, et al. Aligning leadership across systems and organizations to develop a strategic climate for evidence-based practice implementation. Annu Rev Public Health 2014;35:255-74.

51. Ehrhart MG, Aarons GA, Farahnak LR. Assessing the organizational context for EBP implementation: the development and validity testing of the Implementation Climate Scale (ICS). Implement Sci 2014;9:157.

52. Weiner BJ, Belden CM, Bergmire DM, et al. The meaning and measurement of implementation climate. Implement Sci 2011;6:78.

53. Aarons GA, Sommerfeld DH. Leadership, innovation climate, and attitudes toward evidence-based practice during a statewide implementation. J Am Acad Child Adolesc Psychiatry 2012;51:423-31.

54. Barling J, Loughlin C, Kelloway EK. Development and test of a model linking safety-specific transformational leadership and occupational safety. J Appl Psychol 2002;87:488-96.

55. Hong $\mathrm{Y}$, Liao $\mathrm{H}, \mathrm{Hu} \mathrm{J}$, et al. Missing link in the service profit chain: a meta-analytic review of the antecedents, consequences, and moderators of service climate. J Appl Psychol 2013;98:237-67.

56. von Thiele Schwarz U, Hasson H, Tafvelin S. Leadership training as an occupational health intervention: improved safety and sustained productivity. Saf Sci 2016;81:35-45.

57. Gurt J, Schwennen C, Elke G. Health-specific leadership: Is there an association between leader consideration for the health of employees and their strain and well-being? Work Stress 2011;25:108-27.

58. Lewis R, Donaldson-Fielder $\mathrm{E}$. The vital role of line managers in managing psychosocial risks. In: Biron C, Karanika-Murray M, Cooper C, eds. Improving Organizational Interventions for Stress and Well-being: Addressing Process and Context. Oxford: Routledge, 2012.

59. Lundmark R, Hasson $\mathrm{H}$, von Thiele Schwarz U, et al. Leading for change: line managers' influence on the outcomes of an occupational health intervention. Work Stress 2017;31:276-96.

60. Aarons GA, Ehrhart MG, Farahnak LR. The Implementation Leadership Scale (ILS): development of a brief measure of unit level implementation leadership. Implement Sci 2014;9:45.

61. Randall R, Nielsen K, Tvedt SD. The development of five scales to measure employees' appraisals of organizational-level stress management interventions. Work Stress 2009;23:1-23.

62. Richter A, von Thiele Schwarz U, Lornudd C, et al. iLead-a transformational leadership intervention to train healthcare managers' implementation leadership. Implement Sci 2016;11:1-13.

63. Furr M. Scale Construction and Psychometrics for Social and Personality Psychology. London, United Kingdom: SAGE Publications Ltd, 2013.
64. Hasson H, von Thiele Schwarz U. How can research contribute to more useful evidence? Getting everyone on the same page: Co-created program logic (COP). Useful Evidence: Adherence and Adaptations (in Swedish: Användbar evidens: om följsamhet och anpassningar). Stockholm: Natur \& Kultur, 2017:210-1.

65. Lee A, Carpenter NC. Seeing eye to eye: A meta-analysis of selfother agreement of leadership. Leadership Q 2017.

66. Fleenor JW, Smither JW, Atwater LE, et al. Self-other rating agreement in leadership: A review. Leadersh Q 2010;21:1005-34.

67. Dvir T, Eden D, Avolio BJ, et al. Impact of Transformational Leadership on Follower Development and Performance: A Field Experiment. Acad Manage J 2002;45:735-44.

68. Kelloway EK, Barling J, Helleur J. Enhancing transformational leadership: the roles of training and feedback. LODJ 2000;21:145-9.

69. Statistics Sweden. Theme Labor market, report. Sweden: Statistics Sweden, 2015:4. Trained health and social care workers - today and in the future.

70. Bass BM, Yammarino FJ. Congruence of Self and Others' Leadership Ratings of Naval Officers for Understanding Successful Performance. Appl Psychol 1991;40:437-54.

71. Bass BM. Two Decades of Research and Development in Transformational Leadership. EJWOP 1999;8:9-32.

72. Hoyle RH. Confirmatory factor analysis. Handbook of applied multivariate statistics and mathematical modeling. San Diego, CA, USA: Academic Press, 2000:465-97.

73. Byrne B. Structural Equation Modeling with AMOS: Basic Concepts, Applications, and Programming. $2^{\text {nd }}$ ed. London: Routledge, 2010.

74. Lt H, Bentler PM. Cutoff criteria for fit indexes in covariance structure analysis: conventional criteria versus new alternatives. Struc Equ Modeling 1999;6:1-55.

75. Marsh HW, Hau K-T, Wen Z. In Search of Golden Rules: Comment on Hypothesis-Testing Approaches to Setting Cutoff Values for Fit Indexes and Dangers in Overgeneralizing Hu and Bentler's (1999) Findings. Struct Equ Modeling 2004;11:320-41.

76. Bollen KA. Structural Equations with Latent Variables. New York: John Wiley \& Sons, Inc, 1989.

77. Clinton-McHarg T, Yoong SL, Tzelepis F, et al. Psychometric properties of implementation measures for public health and community settings and mapping of constructs against the Consolidated Framework for Implementation Research: a systematic review. Implement Sci 2016;11:148.

78. Hox JJ. Multilevel analysis: Techniques and applications. 2 edn. New York: Routledge, 2010.

79. Enders CK, Tofighi D. Centering predictor variables in cross-sectional multilevel models: a new look at an old issue. Psychol Methods 2007;12:121-38.

80. Hair JF TR, Anderson RE, Black W. Multivariate data analysis. London: Prentice-Hall, 1998.

81. Aarons GA, Hurlburt M, Horwitz SM. Advancing a conceptual model of evidence-based practice implementation in public service sectors. Adm Policy Ment Health 2011;38:4-23.

82. Aarons GA. Transformational and transactional leadership: association with attitudes toward evidence-based practice. Psychiatr Serv 2006;57:1162-9.

83. Hunter ST, Bedell-Avers KE, Mumford MD. The typical leadership study: Assumptions, implications, and potential remedies. Leadersh Q 2007;18:435-46.

84. Hinkin TR. A Brief Tutorial on the Development of Measures for Use in Survey Questionnaires. Organ Res Meth 1998;1:104-21.

85. Glasgow RE, Riley WT. Pragmatic measures: what they are and why we need them. Am J Prev Med 2013;45:237-43. 